\title{
Delayed Breast Cellulitis following Surgery for Breast Cancer: A Literature Review
}

\author{
Georgios Exarchos $^{a} \quad$ Linda Metaxa $^{\mathrm{b}} \quad$ Anastasia Constantinidou $^{\mathrm{c}}$ \\ ${ }^{a}$ 2nd Department of Surgery, National and Kapodistrian University of Athens, Athens, Greece; \\ ${ }^{b}$ Radiology Department, St Bartholomew's Hospital, London, UK; \\ ${ }^{c}$ Medical School University of Cyprus and the BoC Oncology Centre, Nicosia, Cyprus; \\ d 1st Department of Surgery, National and Kapodistrian University of Athens, Athens, Greece
}

Michalis Kontos ${ }^{d}$

\section{Keywords}

Delayed breast cellulitis, DBC - Breast-conserving surgery · Radiotherapy · Infection · Axillary node dissection · Lymphatics

\section{Abstract}

Background: Delayed breast cellulitis (DBC) is a relatively rare complication following breast-conserving surgery. It is often challenging to distinguish DBC from other clinical conditions such as postoperative infection, inflammatory reaction following radiation, and recurrent inflammatory carcinoma. The definition of DBC, diagnostic approach, and treatment are not well established in the literature. Methods: We performed a literature search with the keywords 'Delayed breast cellulitis' and 'Breast conservation therapy cellulitis', without limitations to the dates or the article types, in the PubMed database. Information about the number of cases with $\mathrm{DBC}$, the age of the patients, the interval between the onset of symptoms and the time of surgery or radiotherapy, and the type and outcome of DBC treatment were reviewed and tabulated. Results: We identified only 5 papers that were absolutely related to our subject, reflecting the fact that 'delayed breast cellulitis' is a fairly unknown term and the condition is rather underreported. Although most agree that DBC is primarily an aseptic inflammatory process, bacterial growth may contribute to its development or recurrence. Obesity, breast size, location of the breast tumor, removal of the axillary lymph nodes, and connective tissue disorders are considered as risk factors. There is no clear evidence on how DBC should be best managed. Antibiotic treatment is controversial, and many authors suggest anti-inflammatory agents or sole observation. Prevention of lymph stasis and its consequences with massage and skin care may be helpful. Despite the fact that malignancy is rare, in cases where the condition persists for more than 4 months, a core biopsy should be performed to rule out recurrent or second primary carcinoma. Conclusion: The correct diagnostic approach is essential as it provides patients with reassurance, minimizes anxiety, and prevents unnecessary medical investigations, treatments, and costs.

(c) 2018 S. Karger GmbH, Freiburg

\section{Introduction}

Breast-conserving surgery with adjuvant radiotherapy has become well-established in the treatment of early breast cancer, providing better cosmetic results compared to mastectomy without compromising oncological safety.

Despite its popularity, there have been several complications associated with breast conservation. Amongst them, delayed breast cellulitis (DBC) is a fairly unknown and thus rather underreported condition, which is however being increasingly identified in these patients. With an incidence of 3-5\% [1-3], it often poses a diagnostic and therapeutic challenge. Its main clinical significance is that it must be distinguished from conditions which require aggressive treatment, namely postoperative infection or recurrent carcinoma. It is also often confused with radiotherapy-related

\section{KARGER}

() 2018 S. Karger GmbH, Freiburg

E-Mail karger@karger.com

www.karger.com/brc
Dr. Georgios Exarchos

2nd Department of Surgery

National and Kapodistrian University of Athens, Aretaieion Hospital

76 Vas. Sofias Ave., 11528 Athens, Greece

exarchos@ doctors.org.uk 
changes. The correct diagnostic approach provides patients with reassurance, minimizes anxiety, and prevents unnecessary medical investigations, treatments, and costs.

\section{Materials and Methods}

We performed a literature search with the keywords 'Delayed breast cellulitis' and 'Breast conservation therapy cellulitis', without limitations to the dates or the article types, in the PubMed database. The search produced several papers but identified only 5 that were absolutely related to our subject; interestingly, those were relatively old publications. This probably reflects the fact that 'delayed breast cellulitis' is a fairly unknown term and the condition is rather underreported. Furthermore, we added to our search the keywords 'complications breast surgery' in an attempt to expand the results and identify also cases that were reported under the general term 'breast cellulitis' but may in fact have been cases of DBC. Information about the number of cases with DBC, the age of the patients, the interval between the onset of symptoms and the time of surgery or radiotherapy, and the type and outcome of DBC treatment were reviewed and tabulated.

\section{Definition}

DBC is defined as a clinical condition comprising diffuse breast erythema, edema, tenderness, and mild warmth, occurring at least 3 months following breast-conserving surgery and more than 3 weeks after completion of radiotherapy $[4,5]$. There are no major systemic symptoms or laboratory findings; mild symptoms, if present, most commonly include low fever and leukocytosis; blood cultures are negative.

As no overall agreement exists on its definition, other authors describe DBC as presenting after a median interval of 10 months from surgery and symptoms resolving within 7 months [3]. Furthermore, Rescigno et al. [6] introduced the terms 'chronic recurrent cellulitis' and 'chronic persistent cellulitis', rather arbitrarily defined. In this report, chronic recurrent cellulitis refers to recurrent episodes of cellulitis requiring treatment in a time interval of 6 weeks to 17 months and chronic persistent cellulitis to a single episode of cellulitis persisting despite treatment for 4-17 months.

\section{Incidence}

The reported incidence of DBC varies widely. It can be from 3 to $8 \%$ following breast-conserving treatment [1-4] but is often considerably underreported: in a prospective study of 3,762 patients, 22 patients presented with postoperative breast erythema, but only 2 were given a diagnosis of breast cellulitis [7] (table 1).

\section{Etiology and Mechanism}

Most authors agree that DBC is a primarily aseptic inflammatory process, although bacterial growth may play a role in its development. The subcutaneous and subdermal lymphatic drainage is impaired due to fibrosis secondary to extensive axillary dissection and/or recurrent episodes of infection which are more often seen after multiple seroma aspirations or other surgical complications. In addition, radiotherapy involving the upper outer quadrant of the breast or/and the axilla compromises the lymphatic flow. Poor lymphatic drainage leads to lymph stasis, lymphedema, and subsequently DBC [3].

Although, as described above, infection is not the main underlying mechanism of DBC $[1,2]$, some authors believe that bacterial proliferation could also play a role; lymphatic obstruction predisposes to infection due to stagnating fluid which is an excellent medium for bacterial growth. This is based on the observation that, in several cases, symptoms resolved following antibiotic treatment despite nil growth in fluid aspirate and blood cultures [2].

Extrapolating knowledge from the much more extensively described arm lymphedema, it seems that lymphatic stagnation may also be related to cellulitis. Axillary clearance causes impaired lymphatic drainage, which alone or in combination with radiotherapyinduced fibrosis leads to lymph stasis and arm lymphedema. The latter causes further lymph stasis and increases the risk of infection in the ipsilateral breast and subsequently of DBC, putting patients at a higher risk of bacterial overgrowth and ultimately infectious cellulitis, as the lymphatics are the main pathway to drain away bacteria [8]. Once infection takes place, it increases the capillary permeability causing worsening of the lymphedema, and the process enters a vicious circle [9]. It is rational to hypothesize that cellulitis of the arm secondary to arm lymphedema shares the same pathophysiology as DBC.

\section{Risk Factors}

With regard to the risk factors for DBC, there are specific patient or/and tumor characteristics that have been identified.

Obesity and breast size are associated with $\mathrm{DBC}[3,4,10]$, probably due to susceptibility to lymph stasis, although there may be opposing reports [3]. Obesity has been identified as an independent risk factor for DBC and is a cause of arm edema as well.

Tumor location is also significant, as treatment of cancers in the upper outer quadrant or the tail of the breast is more likely to cause lymphatic blockage and subsequently DBC [4].

Other factors disrupting lymphatic drainage, namely radiotherapy and axillary dissection, may also be responsible for DBC. Rescigno et al. [6] describes the radiotherapy-induced desquamation effect, a process which may allow excessive bacterial colonization from the skin. Radiotherapy also causes squamous metaplasia of the duct epithelium and epitheliosis, which may obstruct mammary ducts and initiate a periductal inflammatory reaction and/or bacterial overgrowth.

Regarding axillary surgery, removal of $>5$ axillary lymph nodes has been reported to be highly associated with $\mathrm{DBC}$, and this was statistically significant [4]. Although not statistically proven in all studies, axillary node dissection has often been reported to precede DBC. Zippel et al. [3] showed that all 16 women who developed 
Table 1. Reported delayed breast cellulitis (DBC) in the literature: incidence, timing, and treatment

\begin{tabular}{|c|c|c|c|c|c|c|c|c|}
\hline \multirow{2}{*}{$\begin{array}{l}\text { Author } \\
\text { [ref.] }\end{array}$} & \multirow{2}{*}{$\begin{array}{l}\text { Patients, } \\
\mathrm{n}(\%)\end{array}$} & \multirow{2}{*}{$\begin{array}{l}\text { Mean } \\
\text { age, } \\
\text { years }\end{array}$} & \multirow{2}{*}{$\begin{array}{l}\text { Time from } \\
\text { surgery/RT }\end{array}$} & \multicolumn{3}{|c|}{ Treatment of DBC, $\mathrm{n}$} & \multirow[t]{2}{*}{ DBC follow-up } & \multirow[t]{2}{*}{ Late follow-ups } \\
\hline & & & & $\begin{array}{l}\text { obser- } \\
\text { vation }\end{array}$ & $\mathrm{AB}$ & $\begin{array}{l}\text { anti- } \\
\text { inflammatories }\end{array}$ & & \\
\hline $\begin{array}{l}\text { Zippel et al. } \\
\text { [3] }\end{array}$ & $\begin{array}{l}16 / 468 \\
(3.4)\end{array}$ & 63 & $\begin{array}{l}\text { median } 10 \text { (range } \\
4-15) \mathrm{m} \text { after surgery; } \\
7 \text { p: } 2 \mathrm{~m} \text { or later post } \\
\text { RT }\end{array}$ & $13 / 16$ & $3 / 16$ & 0 & $\begin{array}{l}\text { resolved in } 16 / 16 p \\
\text { mean time } 7.5 \mathrm{~m}\end{array}$ & $\begin{array}{l}\text { none had recurrent ma- } \\
\text { lignancy } \\
1 \text { p had mastectomy } \\
\text { because of diffuse fi- } \\
\text { brotic reaction }\end{array}$ \\
\hline $\begin{array}{l}\text { Staren et al. } \\
{[2]}\end{array}$ & $10 / 184(5)$ & 57 & $\begin{array}{l}3 \mathrm{~m} \text { or later after } \\
\text { lumpectomy or } 6 \mathrm{~m} \\
\text { after RT }\end{array}$ & $3 / 10$ & $5 / 10$ & $2 / 10$ & $\begin{array}{l}\text { resolved in } 5 \mathrm{p} \\
\mathrm{n}=4 \text { within } 2 \mathrm{w} \\
\mathrm{n}=1 \text { within } 2 \mathrm{~m} \\
\text { treatment } \\
\quad \cdot 3 \text { : AB } \\
\quad \cdot 1 \text { : anti-inflammatories } \\
\text { persisted in } 5 \mathrm{p} \\
\text { (for } 4 \mathrm{~m} \text { to over } 1 \mathrm{y} \text { ) } \\
\text { treatment } \\
\quad \cdot 3 \text { : observation } \\
\quad \cdot 1 \text { : AB } \\
\quad 1 \text { : anti-inflammatories }\end{array}$ & $\begin{array}{l}1 \mathrm{p} \text { with persistence of } \\
\text { symptoms developed } \\
\text { recurrent malignancy }\end{array}$ \\
\hline $\begin{array}{l}\text { Miller et al. } \\
\text { [1] }\end{array}$ & $8 / 181(4.4)$ & 62 & $2-16 \mathrm{~m}$ post $\mathrm{RT}$ & 0 & $\begin{array}{l}\text { 8/8 } \\
-6 / 8 \text { oral } \mathrm{AB} \\
\quad 4 / 6: 1 \text { course of } \mathrm{AB} \\
\quad 2 / 6: 2-3 \text { courses of } \\
\quad \mathrm{AB} \\
-2 / 8 \text { required hospital } \\
\text { admission for } \mathrm{IV} \mathrm{AB}\end{array}$ & 0 & resolved in $8 / 8 p$ & $\begin{array}{l}\text { no cases of recurrent } \\
\text { malignancy }\end{array}$ \\
\hline $\begin{array}{l}\text { Rescigno } \\
\text { et al. [6] }\end{array}$ & $11 / 181(6)$ & NA & $4.5 \mathrm{~m}$ post $\mathrm{RT}$ & 0 & $11 / 11$ & 0 & $\begin{array}{l}\text { resolved in } 5 / 11 p \\
\cdot 2 / 5 \text { oral } \mathrm{AB} \\
\cdot 3 / 5 \mathrm{IV} \mathrm{AB} \\
\text { recurrence in } 2 p \\
\cdot \text { oral and IV } \mathrm{AB} \\
\text { persistent in } 4 p \\
\cdot \text { oral treatment }\end{array}$ & $\begin{array}{l}\text { no cases of recurrent } \\
\text { malignancy }\end{array}$ \\
\hline $\begin{array}{l}\text { Indelicato } \\
\text { et al. [4] }\end{array}$ & $50 / 601(8)$ & 57 & $7.42 \mathrm{~m}$ post surgery & $3 / 50$ & $\begin{array}{l}46 / 50 \\
(20 \% \text { IV })\end{array}$ & $2 / 50$ & $\begin{array}{l}\text { resolved in } 39 / 50 p(78 \%) \\
\text { persistent in } 11 / 50 \text { p (22\%) }\end{array}$ & $\begin{array}{l}1 \mathrm{p} \text { had a recurrent ma- } \\
\text { lignancy } \\
2 \mathrm{p} \text { had mastectomy } \\
\text { because of pain }\end{array}$ \\
\hline
\end{tabular}

$\mathrm{RT}=$ Radiotherapy; $\mathrm{p}=$ patient $(\mathrm{s}) ; \mathrm{AB}=$ antibiotics; $\mathrm{NA}=$ not applicable; $\mathrm{IV}=$ intravenous; $\mathrm{m}=$ months; $\mathrm{y}=$ years; $\mathrm{w}=$ weeks.

DBC had a mean number of 16 axillary lymph nodes removed and all diagnostic workup (cytology and bacteriology) was negative. Miller et al. [1] found that the cases with DBC had a median number of 25 lymph nodes removed (range 8-35). Finally, Staren et al. [2] reported that 10 out of 184 patients who underwent breast-conserving surgery for malignancy developed DBC, and the axillary dissection specimens contained a mean number of 13.3 nodes.

Finally, connective tissue and related disorders such as Hunter's disease, Hurler's disease, Marfan syndrome, and osteogenesis imperfecta may predispose to DBC. This is due to the deposition of hyaluronic acid in the soft tissue and skin secondary to fibroblast overactivity. Hyaluronic acid has high molecular weight causing water retention, arm edema, and impaired lymphatic drainage, which subsequently may lead to DBC. The same mechanism explains why patients with myxedema are at increased risk of devel- oping cellulitis [11]. Finally, hypothyroidism at diagnosis is also associated with DBC, although it may not be an independent factor [4]. This can be attributed to the infiltration of the skin with glycosaminoglycans and associated water retention with subsequent arm edema, impaired lymphatic drainage, and DBC.

\section{Diagnosis}

The differential diagnosis and management of DBC can be challenging $[2,3]$. DBC mimics and must be distinguished from malignant changes such as recurrent inflammatory carcinoma or angiosarcoma, the latter of which has been linked to impaired lymphatic drainage and chronic breast infection [12-14]. Interestingly, Fodor et al. [15] described 5 cases of angiosarcoma which were preceded 
by a 'distinctive form of perioperative breast cellulitis'. Other clinical entities that should be included in the differential diagnosis are radiation-induced inflammation and subacute radiation dermatitis, cytosteatonecrosis, venous stasis syndrome, granulomatous mastitis, sarcoidosis, foreign body reaction to surgical materials, and pseudosclerodermatous panniculitis [4].

The diagnosis is based on the clinical findings of erythema, tenderness, and edema in the affected breast at least 3 months after breast-conserving surgery and more than 3 weeks following completion of radiotherapy. Laboratory tests or radiologic investigations are not routinely necessary for the diagnosis and are usually negative [4]. Specifically, fluid cultures collected from the breast and blood of patients with DBC are negative $[3,4,6]$. Frequently, diagnosis is purely clinical, no cultures are taken, and patients are treated on an outpatient basis. In persisting cases, ultrasound can be used to rule out fluid collection, blood cultures to diagnose infection, and biopsies for the remote possibility of malignancy $[1,2]$.

Infective cellulitis is generally expected within the first 3 postoperative months and is associated with systemic symptoms, fever, and leukocytosis $[3,4,6,7]$. DBC lacks distinct or erysipeloid edges to the erythema, has a lower incidence of systemic symptoms, and shows a more insidious development and indolent course [4].

\section{Treatment}

There is no clear evidence on how DBC should be best managed. As there is no clear proof of whether bacterial infections have a role in the development of DBC, antibiotic treatment is controversial. Many authors suggest anti-inflammatory agents or sole observation $[1-3,6,16]$ (table 1). In the study by Zippel et al. [3], patients with ultrasound findings of fluid collection underwent fluid aspiration, however cultures were negative. 16 patients were diagnosed with DBC and only 3 received antibiotic treatment with no apparent immediate effect. The remaining 13 underwent observation only and symptoms resolved with no antibiotics, suggesting that this is an aseptic inflammatory process.

On the other hand, Indelicato et al. [4] suggested that DBC should be initially treated with 10-14 days of antibiotics. Invasive investigations prior to an empirical course of antibiotics are discouraged, as they introduce further trauma and risk of infection into an already vulnerable breast tissue and put more strain on the patient. According to this study, $92 \%$ of their patients received empirical antibiotics to cover $\beta$-hemolytic streptococci and Staphylococcus aureus and the majority of them needed no further management. They also stressed the importance of educating patients with regard to signs and symptoms of DBC in order to seek an early surgical review.

In the report by Staren et al. [2], oral antibiotics were administered in 5 patients and 4 of them had resolution of symptoms within 1-2 weeks of treatment. The 1 patient in whom the cellulitis did not resolve with antibiotics underwent a core biopsy which showed chronic inflammatory changes. Anti-inflammatory agents were given in 2 patients and symptoms resolved within 2 weeks to 7 months; observation alone was decided in 3 patients.
Although malignancy is rare, if the condition persists for more than 4 months, a core biopsy should be performed to rule out recurrent or primary carcinoma. Staren et al. [2] described 5 cases of persistent cellulitis over 4 months that underwent core biopsy; 1 of those was proven to harbor malignancy. Indelicato et al. [4] also had 1 case of recurrence malignancy in their series of patients with DBC; however, no further information is provided.

Knowing that arm lymphedema increases the risk of DBC, Miller et al. [1] suggested patient education on breast and arm lymphedema management, which may lead to a shift from secondary treatment to primary prevention. In outpatient breast clinics or lymphedema clinics, patients are shown how to perform lymphedema massage, compression therapy, skin care, and exercise with the aim to restore the balance between the lymphatic protein load and lymph transport [17]. In this study, 8 out of 181 patients who underwent breast conservation and axillary node clearance presented with DBC. 6 of 8 cases responded to outpatient antibiotics with resolution of symptoms; 4 of those responded to a single dose of oral antibiotics and the remaining 2 additionally required 1 or 2 doses. 2 out of the total 8 cases with severe symptoms (fever, increased white blood cell count but negative blood cultures) required hospital admission and intravenous antibiotics [1].

In the study by Rescigno et al. [6], 5 out of 11 patients were treated with antibiotics with symptoms resolving within 1-8 weeks. 2 out of 11 patients presented with chronic recurrent cellulitis (interval from radiotherapy to cellulitis 30-52 months) and were treated with oral antibiotics in most cases. 4 out of 11 patients developed chronic persistent cellulitis (interval from radiotherapy to cellulitis 3-4 months). 1 patient was taken off antibiotics after 1 year and treated with topical steroid cream with improvement of symptoms.

\section{Conclusion}

DBC is a clinical condition with diffuse breast erythema, edema, tenderness, and slight warmth, occurring at least 3 months following breast-conserving surgery and more than 3 weeks after concluding radiotherapy because of altered lymphatic circulation. There are no major systemic symptoms, but if symptoms occur, they are mild with low-grade leukocytosis and fever; blood cultures are negative. This clinical pattern suggests a different pathogenesis from common postsurgical infection which usually manifests earlier in the postoperative course. Laboratory or imaging investigations are not needed for the diagnosis. Differential diagnosis should include recurrent/inflammatory breast carcinoma and angiosarcoma, and if symptoms persist after 4 months of treatment, a biopsy is suggested. Patient education on presenting symptoms and managing or even preventing breast lymphedema may optimize the clinical outcome of DBC. It is debatable whether antibiotics are of any benefit despite being frequently given. Anti-inflammatory medications are also occasionally administered. 


\section{Authors' Contribution}

EG, ML, KM: substantial contributions to conception and design; EG, ML, CA, KM: drafting of the manuscript and critical revision for important intellectual content; EG, ML, CA, KM: final approval of the version to be published.

\section{Disclosure Statement}

No funding was received for this study. Data and materials were extracted from published papers available at PubMed. The authors declare no competing interests.

\section{References}

1 Miller SR, Mondry T, Reed JS, Findley A, Johnstone PA: Delayed cellulitis associated with conservative therapy for breast cancer. J Surg Oncol 1998;67:242245.

2 Staren ED, Klepac S, Smith AP, Hartsell WF, Segretti J, Witt TR, Griem KL, Bines SD: The dilemma of delayed cellulitis after breast conservation therapy. Arch Surg 1996;131:651-654.

3 Zippel D, Siegelmann-Danieli N, Ayalon S, Kaufman B, Pfeffer R, Zvi Papa M: Delayed breast cellulitis following breast conserving operation. Eur J Surg Oncol 2003;29:327-330.

4 Indelicato DJ, Grobmyer SR, Newlin H, Morris CG Haigh LS, Copeland EM 3rd, Mendenhall NP: Delayed breast cellulitis: an evolving complication of breast conservation. Int J Radiat Oncol Biol Phys 2006;66: 1339-1346.

5 Dixon JM, Larry MB: Breast cellulitis and other skin disorders of the breast. UpToDate, 2017; www.uptodate.com/contents/breast-cellulitis-and-other-skin-disorders-of-the-breast.

6 Rescigno J, McCormick B, Brown AE, Myskowski PL: Breast cellulitis after conservative surgery and radiotherapy. Int J Radiat Oncol Biol Phys 1994;29:163-168.
7 Froman J, Landercasper J, Ellis R, De Maiffe B, Theede $\mathrm{L}$ : Red breast as a presenting complaint at a breast center: an institutional review. Surgery 2011;149:813819.

8 Bertelli G, Dini D, Forno GG, Gozza A: Preventing cellulitis after axillary lymph node dissection. Am J Med 1994;97:202-203.

9 Simon MS, Cody RL: Cellulitis after axillary lymph node dissection for carcinoma of the breast. Am J Med 1992;93:543-548.

10 Kopanski Z, Wojewoda T, Wojewoda A, SchlegelZawadzka M, Wozniacka R, Suder A, Kosciuk T: Influence of some anthropometric parameters on the risk of development of distal complications after mastectomy carried out because of breast carcinoma. Am J Hum Biol 2003;15:433-439.

11 Smith TJ, Bahn RS, Gorman CA: Connective tissue, glycosaminoglycans, and diseases of the thyroid. Endocr Rev 1989;10:366-391.

12 Benda JA, Al-Jurf AS, Benson AB 3rd: Angiosarcoma of the breast following segmental mastectomy complicated by lymphedema. Am J Clin Pathol 1987;87:651655.
13 Marchal C, Weber B, de Lafontan B, Resbeut M, Mignotte $\mathrm{H}$, du Chatelard PP, Cutuli B, Reme-Saumon M, Broussier-Leroux A, Chaplain G, Lesaunier F, Dilhuydy JM, Lagrange JL: Nine breast angiosarcomas after conservative treatment for breast carcinoma: a survey from French comprehensive Cancer Centers. Int J Radiat Oncol Biol Phys 1999;44:113-119.

14 Strobbe LJ, Peterse HL, van Tinteren H, Wijnmaalen A, Rutgers EJ: Angiosarcoma of the breast after conservation therapy for invasive cancer, the incidence and outcome. An unforeseen sequela. Breast Cancer Res Treat 1998;47:101-109.

15 Fodor J, Orosz Z, Szabo E, Sulyok Z, Polgar C, Zaka Z, Major T: Angiosarcoma after conservation treatment for breast carcinoma: our experience and a review of the literature. J Am Acad Dermatol 2006;54: 499-504.

16 Loprinzi CL, Okuno S, Pisansky TM, Sterioff S, Gaffey TA, Morton RF: Postsurgical changes of the breast that mimic inflammatory breast carcinoma. Mayo Clin Proc 1996;71:552-555.

17 Földi E, Földi M, Clodius L: The lymphedema chaos: a lancet. Ann Plast Surg 1989;22:505-515. 